\title{
'Waifs' and 'Strays': An Examination of Shakespeare's Author Function in Three Apocryphal Plays
}

Andreas P. Bassett

Portland State University

Follow this and additional works at: https://pdxscholar.library.pdx.edu/mcnair Let us know how access to this document benefits you.

\section{Recommended Citation}

Bassett, Andreas P. (2019) '"Waifs' and 'Strays': An Examination of Shakespeare's Author Function in Three Apocryphal Plays," PSU McNair Scholars Online Journal: Vol. 13: Iss. 1, Article 8.

https://doi.org/10.15760/mcnair.2019.13.1.8 
Andreas Bassett 1

"Waifs" and "Strays": An Examination of Shakespeare's Author Function in Three Apocryphal Plays

The immutable "Shakespeare" ascription is the single most critical and operative component of apocryphal Shakespeare works. This one precarious connection to William Shakespeare innately sustains and asserts their historical relevance, demanding attention. C. F. Tucker Brooke first assembled and classified the non-canonical "pseudo-Shakespearian plays" in 1908 and described them as "waifs and strays of the Elizabethan drama, brought together adventitiously from here, there, and everywhere, and with no common bond but that mighty name, beneath whose broad influence they all seek shelter" (vi-vii). Ever since, scholars have cleaved into two divisions Shakespeare's ascribed output: recognized canon and apocrypha of questionable provenance. However, as Peter Kirwan has pointed out, this "“in' or 'out"” binary is a reductive mechanism, one that oversimplifies authorial attribution and "disregard[s] history," therefore rendering itself "theoretically unsatisfactory" (Shakespeare and the Idea of Apocrypha 143). Scholars maintain that these "waifs" and "strays" do not exhibit Shakespeare's signature literary styles - internal dispositions of patterns such as "imagery, linguistic richness, style, cadence, or dramatic mood" (Sharpe 683) — present in the First Folio plays. Yet, title pages that attribute these works to "W. S.," "W. Shakespeare," and even "William Shakespeare," challenge scholars and inextricably link these works to Shakespeare's canon. The ambiguous, and perhaps even criminal, authorial attribution of these works still stymies us today and is one of the many reasons why "the category of Apocrypha remains one of the least-studied aspects of Shakespeare" (Shakespeare and the Idea of Apocrypha 8).

Why does Shakespeare's name and likely variants 'W. Shakespeare' and 'W. S.' appear on the quarto title pages of Thomas Lord Cromwell, The London Prodigal, and A Yorkshire 
Tragedy, and what is this name meant to signify? Most scholars aver that unethical publishers falsely attributed works to Shakespeare in order to exploit his popularity. Grace Ioppolo highlights how, in the late 1590s, playwright names began to appear more frequently on title pages of published plays as certain authors became popular with London audiences: "In the earlier period, plays and acting companies apparently attracted audiences; in the later, at least by 1598 when Shakespeare and other authors' names begin to appear for the first time on Quarto title pages of their plays, authors attracted audiences" (14). Will Sharpe offers one explanation for these potentially spurious attributions: “Shakespeare's name was hot property, and printers and publishers, in the absence of genuine Shakespeare plays, tried to fulfil the demand in other ways" (36). However, this notion that printers and publishers were swindling readers is not always reflected in contemporaneously published editions of plays purported to be the work of other prominent playwrights. Aside from very few blatant attempts to pass off texts as written by Shakespeare, such as publisher and bookseller Thomas Pavier's nebulous involvement in the 1619 False Folio, no surviving documentation exists to support the idea that London publishers and printers in the late 1590 s and early 1600 s regularly profited from such ruses.

The equivocal nature of the Shakespeare name in apocryphal Chamberlain's/King's Men plays Thomas Lord Cromwell, The London Prodigal, and A Yorkshire Tragedy demonstrates that Shakespeare's author function operated outside the conventional dimensions of sole and coauthorial attribution. The Passionate Pilgrim, a poetry anthology published in 1599, was solely attributed to Shakespeare, despite the fact that he was one among many contributors. Surprisingly, as Francis X. Connor has pointed out, The Passionate Pilgrim still managed to produce an overall Shakespearean-themed experience despite its collaborative nature. Such abnormalities are a reminder that Shakespeare's author function performed in distinctive ways 
during the late Elizabethan to early Jacobean era that are now invisible to us. Rather than make inquiries into the unanswerable question of what role Shakespeare had in the creation of these apocryphal works, we should instead explicate how the Shakespeare title page attribution performs and functions, what it accomplishes or signifies, and how it has the ability to activate entire texts by bestowing a sense of historical relevance and agency.

The apocryphal Shakespeare plays Thomas Lord Cromwell, The London Prodigal, and A Yorkshire Tragedy exhibit internal characteristics which are "unequal . . . in literary merit" (Brooke vi) to the works widely accepted as Shakespeare's canon. At the same time, these plays all contain a title page attribution to Shakespeare and list the Chamberlain's/King's Men as the affiliated play company. As a result, these plays lack a cohesive structural relationship; the quality of the internal texts do not correspond to the external Shakespeare name (typically synonymous with dramaturgical brilliance). This is the primary cause for their exclusion from the Shakespeare canon. However, our modern evaluation of Shakespeare's works is problematic. We tend to assume that the quality of pieces in the First Folio are the Shakespeare standard and that he only produced first-rate works. This assumption both constructs and reinforces the canon, but we know that the Shakespeare canon is mutable and fluid. A number of works have entered, exited, and re-entered his oeuvre. The basis for a definitive Shakespearean style and merit are in fact based on a shifting group of works; this inherently complicates scholars' ability to validate or authenticate these apocryphal works.

Gabriel Egan offers one straightforward method in which Shakespeare's canon has historically been recognized: “One seemingly conservative way to define Shakespeare's dramatic canon, then, is to include the thirty-six First Folio plays plus Pericles and The Two Noble Kinsmen" (Taylor and Egan 28). However, Kirwan notes that "the canon has always been in a 
state of steady flux as plays such as Pericles, The Two Noble Kinsmen, Titus Andronicus and Thomas More have moved in and out of favor," which has consequently led us into "a period of increased canonical mobility" ("Canonising the Shakespeare Apocrypha" 540). Several apocryphal plays have entered and exited the canon since the seventeenth century. The 1663 Third Folio added seven plays that were originally printed during Shakespeare's lifetime in quarto format, three of which were Thomas Lord Cromwell, The London Prodigal, and A Yorkshire Tragedy. For sixty-five years these plays were considered equals of the original thirtysix First Folio plays. The 1728 second edition of Alexander Pope's The Works of Shakespear modified the canon by removing the same seven plays. Pope states in his preface, "If I may judge from all the distinguishing marks of [Shakespeare's] style, and his manner of thinking and writing, I make no doubt to declare that those wretched plays, Pericles, Locrine, Sir John Oldcastle, Yorkshire Tragedy, Lord Cromwell, The Puritan, and London Prodigal cannot be admitted as his" (547). Later editions, such as Edward Malone's 1780 A Supplement to the Edition of Shakespeare, reintroduced the apocryphal plays as separate supplemental additions, and nineteenth century anthologies of apocryphal plays, such as William Hazlitt's 1887 The Doubtful Plays of William Shakespeare, began to categorize them as pseudo-Shakespearean. It is also worth noting that at the same time, nineteenth century German critics "declared Thomas Lord Cromwell to be not only unquestionably Shakespeare's but deserving to be classed amoung his best and maturest works" (Maxwell 73). If select apocryphal works have vacillated between acceptance and rejection via the canon, then the canon itself is open-ended; its demarcations are obscure. The solidification of Shakespeare's canon is a contemporary phenomenon, and its artificiality is directly challenged by the existence of enigmatic plays with Shakespeare 
attributions. More often than not, they are ostracized for awkwardly existing in a liminal space between the constructed boundaries of Shakespeare and not-Shakespeare.

When a particular work or group of works exhibits disparate internal qualities at variance with perceived literary precepts of the canon, a problem emerges. As Stephen Orgel admits, the least complicated reaction is to "banish from the canon whatever is considered insufficiently excellent" (Orgel 2), reaffirming the existence of a unified but inflexible body of standards and rules. Orgel states that canon is chiefly "determined initially through contemporary ascriptions, or through a citation in the Stationers' Register, or the inclusion of a play in the first folio, or the publication of a work during Shakespeare's lifetime with his name on it" (3). Though the apocryphal Shakespeare works, which bear Shakespeare's name and were published during his lifetime, continue to be maligned. Margaret de Grazia and Peter Stallybrass emphasize that, "The First Folio's status as 'the chief authority' in determining the Shakespeare canon is also problematic" (261) due to the fluid nature of canons. The relegation and elevation of works on the basis of style with disregard for title page attributions only problematizes the issue of the in/out, Shakespeare/not-Shakespeare binary. The reinforcement and safeguarding of a preconceived authentic Shakespeare canon continues to persist, "although no one truly believes in Shakespeare's sole authorship" (Jansohn 320). This is especially relevant at a time when a number of Shakespeare's works are being reexamined and reclassified as collaborative projects (e.g. Christopher Marlowe is credited as co-author of the three Henry VI plays in The New Oxford Shakespeare: Modern Critical Edition, Thomas Middleton is credited as co-author in Oxford World's Classics Timon of Athens). Christa Jansohn points to Brooke's familial metaphor to explain the web of interrelationships within the apocryphal works that he degradingly refers to as "waifs" and "strays" of Elizabethan/Jacobean drama: "Brooke's 'family' of apocrypha 
consists rather of neglected literary 'children' coming from everywhere and seeking protection under Shakespeare's name, of course, without being able to postulate genuine genealogical relations" (Jansohn 321). The incongruous Thomas Lord Cromwell, The London Prodigal, and A Yorkshire Tragedy share the paternal Shakespeare name, but their internal constituents are disputed by academics as "not sounding like" Shakespeare, "or at any rate they do not sound the way we want Shakespeare to sound" (Orgel 3). According to the fashioned Shakespeare canon, these plays may be inauthentic for failure to be included, "but they may also be evidence that Shakespeare had a greater range of styles than we care for" (Orgel 3). To better understand this fluidity and instability of authorship as well as canon, we may shift to the notion of the Foucauldian author function.

Michel Foucault's lecture "What Is an Author?" examines the complex relationships between text and author, and ultimately constructs what Foucault coins "the author function." In order to differentiate the historical author from the author as a function of discourse, Foucault states, "The links between the proper name and the individual named and between the author's name and what it names are not isomorphic and do not function in the same way. There are several differences" (209-10). In other words, there are a variety of ways in which the multifaceted author presents, represents, and performs himself/herself in texts. There are additional distinctions to be made between historical individual names and their authorial names as well; the proper name "William Shakespeare" on its own does not possess the same faculties as the authorial "Shakespeare" name on a title page of a poem, play, or anthology. Understanding the author in this manner enables us to observe how the Shakespeare name has changed in meaning and signification over time. The idea or spectrum of what society and culture have defined as Shakespeare or Shakespearean is arguably still shifting and always will as more 
interpretations surface and research is conducted. The authorial figure of William Shakespeare was noticeably transformed in his lifetime: he began as a mere proper name, more than likely worked in drama anonymously, he matured into a distinguished and credited poet and later playwright, and eventually his authorial name was applied to title pages of published works that were not included in the posthumous 1623 First Folio. Using the Foucauldian author function as a mode of analysis allows for a comprehensive investigation and explication of Shakespeare's multiple names found on the title pages of The Passionate Pilgrim, Thomas Lord Cromwell, The London Prodigal, and A Yorkshire Tragedy.

Foucault states that the third and fourth characteristics of the author function are "not defined by the spontaneous attribution of a discourse to its producer but, rather, by a series of specific and complex operations," and "not refer[ing] purely and simply to a real individual, since it can give rise simultaneously to several selves, to several subjects" (216). The agents who collated the First Folio in 1623 in essence created the Shakespearean canon, now the standard often deployed to repudiate "lesser" works. Kirwan reiterates this as he states, "the boundaries of the authorial canon are ... designed as protective barriers, given to preserving and containing the authorised canon" ("Canonising the Shakespeare Apocrypha" 543). The Shakespeare brand inherent in the First Folio plays "permits one to group together a certain number of texts" in order to "define them, differentiate them from and contrast them to others" (Foucault 210). While the apocryphal plays may fall under Foucault's "others" category, they may also be vehicles in which one of Shakespeare's "several selves" and "several subjects" has emerged. Foucault also turns to theologian and historian Saint Jerome's four criteria for authenticity which consequently engenders the process of canonization: “(1) if amoung several books attributed to an author one is inferior to the others, it must be withdrawn from the list of the author's 
works ... (2) the same should be done if certain texts contradict the doctrine expounded in the author's other work ... (3) one must also exclude works that are written in a different style, containing words and expressions not ordinarily found in the writer's production ... (4) finally, passages quoting statements made or mentioning events that occurred after the author's death must be regarded as interpolated texts" (214). Saint Jerome's guidelines verge on the emergence of a kind of canon function. It abstracts the author into "a constant level of value," "a field of conceptual or theoretical coherence," and "a stylistic unity," (214) setting rigid requirements for the authentication of works into a unified canon. The removal of works considered to be "inferior" and composed "in a different style" (214) essentially illustrates the inception of the Shakespeare canon and how it has historically regulated itself.

Orgel posits the question, "Is its badness an argument against its authenticity?" (1) in order to point out how subjective qualities such as "badness" or mediocrity of style are used as conditions to invalidate a text's authenticity. Regarding the exclusive canonicity of Shakespeare's body of complete works, Orgel questions the legitimacy of attributions dependent on the ambiguous basis of literary quality because of their presumption that Shakespeare did not produce second-rate work in his career as dramatist. This argument is questionable, but is regularly used as a precondition for authenticating and discrediting works. Orgel stresses that "arguments about the sound of Shakespeare are essentially circular. The question of authenticity, like the question of what constitutes evidence, is profoundly time bound, and different texts have sounded right or wrong at different periods, without much regard to evidence of any sort" (Orgel 3). Orgel's argument underscores the historical malleability of the canon. Though the apocryphal plays Thomas Lord Cromwell, The London Prodigal, and A Yorkshire Tragedy demonstrate Shakespeare attributions which are rejected "on grounds of style" (Bate et al. 300) by virtue of 
literary dissimilarities to the broadly-accepted canon, perhaps these shunned texts do not require authentication from and comparison to the First Folio. These texts conceivably give rise to another identity, a multiple or derivative of Shakespeare; "several selves" or "several subjects" meant to fill a divide left by the canon.

Connor is suspicious of the Foucauldian author function and refrains from using it to examine the collaborative nature of the 1599 poetic anthology The Passionate Pilgrim. He asserts, "There is no need to turn to Foucault in defending $P P$ as a Shakespearian collaborative work ... nor should the historical author be abstracted into an author-function" (126), although, from a modern perspective, the historical author is arguably nothing but a product of discourse. Connor affirms that The Passionate Pilgrim is typically regarded as a "by-product of [Shakespeare's] emerging popularity" (121), and its organization “actually complements Shakespeare's emerging reputation, identifying him with genres and styles with which he had already established himself' (123). This collaborative curio of twenty poems contains only five by Shakespeare despite the "W. Shakespeare" attribution on the title page. The five Shakespearean poems are considered genuine because they appeared in the 1609 collection Shakespeare's Sonnets and the mid-1590s play Love's Labour's Lost. Again, a canonical body in the form of Shakespeare's Sonnets is used as a taxonomical force to emphasize and uphold an authentic/inauthentic "two-tier dichotomy" (Shakespeare and the Idea of Apocrypha 67). Shakespeare's Sonnets echoes the First Folio by validating and protecting its built-in poems while simultaneously invalidating and rejecting others that have surfaced extraneously. Structurally, three-quarters of The Passionate Pilgrim is the work of other poets, yet all of the "poems [Shakespeare] certainly did not write are consistent with his literary work" (Connor 123) in an attempt to shape it into a cohesive work, perhaps signaling an early pre-First Folio 
expression of what later came to be known as "Shakespearean." Lois Potter also views The Passionate Pilgrim as an assemblage of poems with an inchoate Shakespearean style. She states that the "by W. Shakespeare" attribution on the title page "might not only mean written by Shakespeare but also in the persona of Shakespeare" (emphasis added by Potter), and that "the entire 1599 volume could be seen as a tribute to Shakespeare's most popular early writing" (Potter 11). Connor explains how "fourteen of the first fifteen poems that appear before the 'Sonnets' section of the book are plausibly 'Shakespearian'” because around half of the poems "are conventional fourteen-line sonnets," and the other half "all employ the stanza form Shakespeare used in Venus and Adonis" (123). Connor concludes that by instating a Shakespeare attribution, "there is clearly an attempt to edit the volume as a Shakespearian poetic work" (123). Orgel adds that this may "indicate that contemporaries knew something we do not know, and saw things in Shakespeare that we no longer see or have edited out" (4), but the "W.

Shakespeare" attribution may also indicate that Shakespeare's author function operated in ways unfamiliar and unrecognizable to us from a modern standpoint. It is not much of a stretch to postulate that Elizabethan/Jacobean audiences expected, experienced, and contributed to a different kind of author function, one that is no longer available or accessible to modern-day audiences.

The Passionate Pilgrim's "W. Shakespeare” signifier activates a signified Shakespeare author function which in turn generates a Shakespeare sign, a modern-day mode of literary and critical engagement. Connor claims that "not all collaborators deserve topline or title-page credit" (119), intimating that Shakespeare's name functions to consolidate multiple agents under one authoritative aegis. Connor also believes that "recognizing $P P$ as a collaborative work of Shakespeare does not diminish his authorial agency; instead it enhances such agency" (123) 
because it extends and diversifies the range of Shakespeare's authorship. This reduction to a singular representative Shakespeare name is a unifying mechanism that stabilizes the work by transmitting to readers a certain set of expected and conventional qualities, themes, and styles. The authorial name acts as a principle of uniformity which "serves to neutralize the contradictions that may emerge in a series of texts" (Foucault 215). Nevertheless, to modern readers, The Passionate Pilgrim's “W. Shakespeare” signifier promptly invokes Shakespeare's foundational canons (The First Folio and Shakespeare's Sonnets) for guidance; there is an appeal for navigating and critiquing these works. A comparison to the core texts is both natural and inevitable. The renowned authorial name denotes a sense of importance but also exposes our obsession with having to verify the identity of a work's author.

The plays Thomas Lord Cromwell, The London Prodigal, and A Yorkshire Tragedy advertise three different authorial attributions: "W. S." in Thomas Lord Cromwell (1602), "William Shakespeare" in The London Prodigal (1605), and "W. Shakespeare" in A Yorkshire Tragedy (1608). Though all three attributions vary in levels of similitude to the full name "William Shakespeare," historically they have been linked to Shakespeare, the man of the theatre, and, however uncomfortably, to his canonical works. In particular, the initials "W. S." are the most vague out of the three attributions, but Bate maintains that "there is a strong probability that the initials 'W. S.' were intended to give the impression that [Shakespeare] was the author" (11). Shakespeare is considered "the only candidate for W. S. conforming to the model of initials on an early play and then full name on the title page once he was established" (Bate et al. 12), which makes this particular attribution to Thomas Lord Cromwell compatible, despite the academic consensus that Shakespeare's literary style is virtually nonexistent in the play's text. Bate also suggests that "the exclusion of The London Prodigal and A Yorkshire 
Tragedy" from the First Folio "is usually taken to be firm evidence of their inauthenticity" (19). As a result of these "spurious attributions" (Sharpe 35), scholars and researchers have submitted the plays to careful scrutiny, demonstrating how the Shakespearean author function is able to still influence readers centuries later.

Unlike The Passionate Pilgrim, the plays Thomas Lord Cromwell, The London Prodigal, and A Yorkshire Tragedy do not appear to exhibit Shakespearean themes and styles, nor do they seem to imitate Shakespeare's persona. The plays noticeably delve into territories that are, for the most part, unexplored in the First Folio. Gary Taylor notes that around 1605, "London audiences had a growing appetite for the city comedies and city histories being written by Shakespeare's younger contemporaries, and ... that Shakespeare himself was not the man to satisfy that appetite and needed a collaborator to do so" (17). The genres of domestic/city comedy and city history and chronicle history, encompassing stories of everyday people and "the drama of everyday life and death in Shakespeare's England" (Bate et al. 300), supply the underlying structures of these three apocryphal plays. These themes distance these works from the ternary canon, made up of comedies, histories, and tragedies. Thomas Lord Cromwell, the first of the three apocryphal Chamberlain's/King's Men plays to appear in print, in 1602, is "close in tone to other distinctly uncourtly plays with which Shakespeare's name" (Bate et al. 300) eventually became associated with, namely The London Prodigal in 1605 and A Yorkshire Tragedy in 1608.

As Foucault states, "the text always contains a certain number of signs referring to the author" (215). Invoking the First Folio results in the casting of a searchlight for fragments of Shakespeare in other works. For example, the first scene of A Yorkshire Tragedy is considered "rather different from the rest" of the play and "some scholars see Shakespeare's composing, guiding or revising hand within it" (Bate et al. 479). The short first scene is the only scene in the 
play to have named characters and provides an inside look into the life of the unnamed Wife "through the eyes of [her] household" (Bate et al. 479); Sam, a servingman of the unnamed Wife, returns from the country with news that her prodigal husband who has been away for some time has in fact married another woman, "has two or three children by her," and now "beats his wife" (1.32-33). The introduction sets the play's tone for the violent Husband and the entire sixty-two lines incorporate "intense individualization and humanization that - even if the scene is not by Shakespeare - is so characteristic of Shakespeare" (Bate et al. 479). Bate believes that "this opening provided a very Shakespearean beginning to a very memorable short play," even though the rest of $A$ Yorkshire Tragedy has now been "universally attributed to Thomas Middleton" (479). The prominent Shakespeare name in this instance is indicative of some kind of intervention and/or bestowment of authority and significance. Alternatively, as a direct result of the Shakespeare attribution, scholars intentionally look for and sometimes anticipate traces of Shakespeare in the play; something they likely would not do if not for the attribution. Nonetheless, it is evident that this divergent set of plays incorporates and performs multiple Shakespearean author functions. The variations of the Shakespeare name authorize the play by bestowing it with a sense of significance and provenance. The attribution also has the potential to expand the canon.

It is logical to interpret Shakespeare's authorial name via the signifiers "W. S." and "W. Shakespeare" and "William Shakespeare" to mean that the apocryphal Chamberlain's/King's Men plays are trying to re-establish a connection with the rest of Shakespeare's accepted canonical works. At the very least, there is an indeterminate affiliation, albeit a negative one due to the more recent doubt surrounding the apocryphal plays as spurious works because of their initial exclusion from the First Folio. In Thomas Lord Cromwell, The London Prodigal, and A 
Yorkshire Tragedy, the Shakespearean author function operates by creating an imaginary link between the disowned apocryphal plays and the authoritative and patriarchal First Folio. The link hinges solely on the Shakespeare name in conjunction with the affiliated play company. If the playwright's name and play company name are represented together on a title page, then this must be a positive indication of a request to either be authenticated or reconnected with the genuine plays of the First Folio. However, apart from the Shakespeare attribution and identification of the associated play company as the Chamberlain's/King's Men, nothing suggests that the plays Thomas Lord Cromwell, The London Prodigal, and A Yorkshire Tragedy seek acceptance or authentication. This is perhaps why these plays went relatively unnoticed during Shakespeare's lifetime and were not considered for inclusion in the First Folio. It is also worth noting that the 1609 Shakespeare's Sonnets also "went unnoticed because there was little interest in them" (Orgel 4), despite the collection featuring what we typically perceive to be a recognizable Shakespeare attribution. The sense of profound importance and prominence attached to the Shakespeare name is a modern creation. As stated previously, Shakespeare's author function must have operated in vastly different ways in London drama during the 1590s and early 1600s. Not only did audiences engage with Shakespeare on different levels, the signified author perhaps carried more meanings, identities, and signs. While The Passionate Pilgrim emulated a Shakespearean persona without appealing to a governing poetic canon, perhaps these apocryphal plays operate independently and extraneously from the order of the First Folio. If so, then their author function executes and accomplishes rare objectives not found anywhere else in Elizabethan/Jacobean drama.

If we contemplate the idea that Thomas Lord Cromwell, The London Prodigal, and A Yorkshire Tragedy are autonomous texts disconnected from the First Folio, then we may view 
them as Shakespearean artifacts demonstrating unconventional and anachronistic functions. If the First Folio aims to consolidate works and preserve the author, then the apocryphal Shakespeare plays stemming from the Chamberlain's/King's Men, hypothetically, act in an inverse way by contributing to non-canonical domains, expanding the range of the author rather than containing it. To modern readers, this operation broadens the scope of Shakespearean authorship in genre and arguably in quality (e.g. "badness" or the capacity to create mediocre works), which in turn challenges preconceived notions of literary style. It also actuates a modernday invention; a specific mode of discourse in how we approach texts with a locked-in sacrosanct mindset. The Shakespeare name activates a set of principles (language usage, recurring themes derived from the canon, etc.) that modern readers refer to when engaging with a Shakespearean text. When presented with the plays Thomas Lord Cromwell, The London Prodigal, and A Yorkshire Tragedy and their Shakespeare attributions, readers immediately formulate expectations and biases based on preconceptions. Previous readings of Shakespeare can and will dictate how some readers engage with unfamiliar and apocryphal works. The Shakespearean author function also creates a shield of guardianship for the multiple agents that produced a play. This shield may function to protect the integrity of a text by brandishing the reputable Shakespeare name, which is appropriate if we consider how "Protecting and preserving Shakespeare as an authorial brand on stage at least was an apparent long-term strategy of his company post-1599" (Sharpe 37). "Shakespeare" is essentially utilized as a proxy to integrate the play as a whole. The often similar and sometimes identical author names found in select apocryphal plays appear to not always possess the same author function. Thomas Lord Cromwell's "W. S." has led researchers to consider alternative authors such as Wentworth Smith and William Sly and the usage of initials has been speculated to mean that the author was still in 
the early stages of his career. The opaque attribution of the play and its resultant author function open the door to a wide range of interpretations and possibilities. By being unbound to an explicit authorial name, and therefore a canon, the work remains a malleable artifact capable of independently shifting in, out, and between canons. In comparison, The London Prodigal's "William Shakespeare," an identical match to the true Shakespeare name, has the reverse effect. On the surface, the indistinguishable Shakespeare name produces an impression of credibility. The full authorial name comes attached with an established repertoire and conveys to readers certain axioms derived from comparable plays by the same author. The plays' attributions demonstrate the versatility of the Shakespearean author function across four centuries.

The decision to relegate plays such as Thomas Lord Cromwell, The London Prodigal, and A Yorkshire Tragedy to the subcategory of Shakespeare apocrypha devalues their literary worth. It implies that the apocrypha's counterpart, the Shakespeare canon, is hierarchically superior in quality and in genuineness. This inadvertently strengthens the in/out, authentic/inauthentic binary by suggesting that there is a built-in Shakespearean order. However, as Kirwan points out, "the notion of impurities in the canon renders canon itself a problematic category" (Shakespeare and the Idea of Apocrypha 10). Including the apocryphal plays as supplemental additions still reinforces the idea that a homogeneous group of true Shakespeare works exists. Moreover, the disparaging descriptors used in the past by academics to describe some of the apocryphal plays are equally damaging. Brooke's usage of terms such as "waifs" and "strays" (vi) and Algernon Charles Swinburne's diatribe, “shapeless, spiritless, bodiless, soulless, senseless, helpless, worthless rubbish" (Maxwell 72), further undermine the already disadvantaged status of the apocryphal Shakespeare plays. If there is to be a "destabilisation of the Shakespeare Apocrypha," and the recognition of "the fluidity of canonical boundaries" (Shakespeare and the Idea of 
Apocrypha 209), then we may have the freedom to treat the works of Shakespeare as more of an intricate network as opposed to sets of segregated categories. The "authentic" Shakespeare may also not be able to continue if the barriers of canon and apocrypha collapse. Shifting our understanding of the Shakespeare identity and works in this manner will allow for more profitable opportunities to examine how aspects of Shakespeare's authorship, like the author function, have operated and still operate in extraordinary ways that we are still uncovering. Without the black and white mindset that the First Folio and Apocrypha subconsciously produce, a more nuanced perspective of Shakespearean authorship may arise; one that takes the "waifs" and "strays" into consideration as being both independently functional and just as important as all of Shakespeare's canonical plays. 


\section{Works Cited}

Bate, Jonathan, et al. William Shakespeare and Others: Collaborative Plays. Palgrave Macmillan, 2013.

Connor, Francis. "Shakespeare, Poetic Collaboration and the Passionate Pilgrim." Shakespeare Survey, vol. 67, 2014, pp. 119-130.

De Grazia, Margreta, and Peter Stallybrass. "The Materiality of the Shakespearean Text." Shakespeare Quarterly, vol. 44, no. 3, 1993, pp. 255-283.

Foucault, Michel. "What Is an Author?" Aesthetics, Method, and Epistemology, edited by James D. Faubion, New Press, W.W. Norton, 1997, pp. 205-222.

Ioppolo, Grace. Dramatists and Their Manuscripts in the Age of Shakespeare, Jonson, Middleton and Heywood: Authorship, Authority and the Playhouse. Routledge, 2005.

Jansohn, Christa. “The Shakespeare Apocrypha: A Reconsideration.” English Studies, vol. 84, no. 4, 2003, pp. 318-329.

Kirwan, Peter. "Canonising the Shakespeare Apocrypha: Shakespeare, Middleton and Co-Existent Canons.” Literature Compass, vol. 9, no. 8, 2012, pp. 538-548.

Kirwan, Peter. Shakespeare and the Idea of Apocrypha: Negotiating the Boundaries of the Dramatic Canon. Cambridge University Press, 2015.

Maxwell, Baldwin. Studies in the Shakespeare Apocrypha. King's Crown Press, 1956.

Orgel, Stephen. “The Authentic Shakespeare.” Representations, vol. 21, no. 21, 1988, pp. 1-25. Pope, Alexander, et al. The Works of Alexander Pope: Volume 10. Murray, 1886.

Potter, Lois. "Involuntary and Voluntary Poetic Collaboration: The Passionate Pilgrim and Love's Martyr." Shakespeare and His Collaborators over the Centuries. Drábek, Pavel, et al., editors. Cambridge Scholars Press, 2008, pp. 5-18. 
Shakespeare, William. A Yorkshire Tragedy. William Shakespeare and Others: Collaborative Plays. Bate, Jonathan, et al. Palgrave Macmillan, 2013, pp. 481-501.

Shakespeare, William, and Brooke, C.F. Tucker. The Shakespeare Apocrypha; Being a Collection of Fourteen Plays Which Have Been Ascribed to Shakespeare. Clarendon Press, 1908.

Sharpe, Will. "Framing Shakespeare's Collaborative Authorship.” Shakespeare Survey, vol. 67, 2014, 29-43.

Taylor, Gary, and Egan, Gabriel. The New Oxford Shakespeare: Authorship Companion. First ed., Oxford University Press, 2017.

Taylor, Gary. "Why Did Shakespeare Collaborate?” Shakespeare Survey, vol. 67, 2014, 1-17 